\title{
A IMPORTÂNCIA DAS DIGITAL SKILLS EM TEMPOS DE CRISE: ALGUNS APLICATIVOS UTILIZADOS DURANTE O ISOLAMENTO SOCIAL DEVIDO À PANDEMIA DO COVID-19
}

\author{
Lucas Ramon dos Santos Hermógenes \\ Engenheiro de Produção e pesquisador do Laboratório de Estudos de Governança, Gestão e \\ Otimização pelo Centro Universitário Augusto Motta (UNISUAM), RJ, Brasil \\ E-mail: lucas.hermogenes@outlook.com \\ Marcos dos Santos \\ Professor do Programa de Pós-graduação em Sistemas e Computação (PPgSC) do \\ Instituto Militar de Engenharia (IME), RJ, Brasil \\ E-mail:marcosdossantos@ime.eb.br \\ Priscila Fernandes do Nascimento \\ Graduada em Engenharia Mecânica pelo Centro Universitário \\ Augusto Motta (UNISUAM), RJ, Brasil \\ E-mail: priscila_f.n@hotmail.com \\ Luiz Frederico Horácio de S. de B. Teixeira \\ Oficial Superior da Marinha do Brasil em serviço no Centro de Análise \\ de Sistemas Navais (CASNAV), RJ, Brasil \\ E-mail: frederico.horacio@gmail.com
}

\begin{abstract}
RESUMO
Devido à pandemia da doença COVID-19 (Corona Virus Disease 2019), causada pelo vírus SarsCov-2 (Severe acute respiratory syndrome Coronavirus 2), as organizações foram influenciadas a mudarem suas rotinas de trabalho para contribuir com a redução de casos do vírus mundialmente. Em virtude da alta velocidade de contágio e falta de medicamentos efetivos para o tratamento da doença, a Organização Mundial da Saúde (OMS) orientou que a melhor opção seria o isolamento social. Algumas empresas adotaram a prática do Home Office com o objetivo de continuarem entregando resultados positivos e, paralelamente, tentarem frear um outro problema que pode ser ocasionado pela pandemia: o desemprego em massa e uma crise econômica global. Visando contribuir com a sociedade nas medidas de mitigação da pandemia da COVID-19, o presente trabalho foi fundamentado na apresentação das melhores práticas que podem auxiliar nas atividades de trabalho remoto. $O$ objetivo do trabalho é, portanto, apresentar um panorama atualizado sobre as Digital Skills no processo decisório, na análise de dados, na comunicação coorporativa e no aumento de produtividade, em meio às medidas de isolamento social para evitar a propagação do vírus Sars-Cov-2.
\end{abstract}

Palavras-chave: COVID-19. Coronavírus. Produtividade. Tomada de decisão. Digital Skills. 


\title{
THE IMPORTANCE OF DIGITAL SKILLS IN TIMES OF CRISIS: SOME APPLICATIONS USED DURING SOCIAL ISOLATION DUE TO THE COVID-19 PANDEMIC
}

\begin{abstract}
Due to the pandemic of the disease COVID-19 (Corona Virus Disease 2019), caused by the SarsCov-2 virus (Severe acute respiratory syndrome Coronavirus 2), organizations were influenced to change their work routines to contribute to the reduction of cases of virus worldwide. Due to the high rate of contagion and the lack of effective drugs for the treatment of the disease, the World Health Organization (WHO) advised that the best option would be social isolation. Some companies have adopted the practice of the Home Office in order to continue delivering positive results and, at the same time, try to curb another problem that can be caused by the pandemic: mass unemployment and a global economic crisis. Aiming to contribute to society in the COVID19 pandemic mitigation measures, the present work was based on the presentation of the best practices that can assist in remote work activities. The objective of the work is, therefore, to present an updated panorama on Digital Skills in the decision-making process, in data analysis, in corporate communication and in the increase of productivity, in the midst of social isolation measures to prevent the spread of the Sars-Cov virus -2 .
\end{abstract}

Keywords: COVID-19. Coronavirus. Productivity. Decision Making. Digital Skills. 


\section{INTRODUÇÃO}

A humanidade passou por diversas transformações ao longo dos anos, de modo que o homem precisou se adaptar e se reinventar diversas vezes. O mundo vivenciou guerras, catástrofes naturais, atentados e doenças dos mais variados tipos.

As crises e dificuldades, quer tenham sido sociais, industriais ou mercadológicas, contudo, incentivaram a alavancagem do processo criativo. Realizar uma atividade complexa de forma mais rápida e simples, mediante o auxílio de ferramentas, foi o grande passo para que a sociedade se desenvolvesse ao longo do tempo. Desta forma, surgiram inovações como a roda, as máquinas industriais, os automóveis, aviões, homens e mulheres viajando ao espaço, o desenvolvimento da internet, entre outros. Esta evolução continua e, atualmente, já é possível trabalhar com o auxílio de robôs e de Inteligência Artificial (IA).

O avanço tecnológico é, portanto, um processo constante. Há décadas, a sociedade tinha necessidade de enviar telegramas e cartas, a comunicação era precária, os dispositivos de telefone eram maiores e alguns computadores ocupavam salas inteiras. Atualmente é possível acessar notícias em tempo real através de aparelhos que cabem na palma das mãos, se comunicar com qualidade e agilidade e estar conectado em diversos dispositivos e aplicativos de forma integrada. Os computadores e aparelhos celulares ficaram menores, mais rápidos e mais eficientes e os meios de comunicação avançaram significativamente. Neste contexto, no século XXI, seria praticamente impossível processar o mesmo volume de informações e realizar as mesmas atividades em um ambiente de trabalho ou pesquisa sem o apoio de nenhum dispositivo tecnológico.

Nos dias atuais, faz-se necessário ter domínio de ferramentas que deixem a rotina da sociedade e das organizações mais flexíveis, que contribuam para o aumento da produtividade e que facilitem a mobilidade em geral. O fluxo de informações e o processo de tomada de decisão precisam continuar acontecendo, independente dos fatores externos ameaçarem ou não as rotinas internas de trabalho e pesquisa. É necessário avaliar e buscar alternativas para que os negócios, a economia, a educação e a sociedade não parem por influência de ameaças que estão fora do controle das organizações. Ademais, é mandatório que os profissionais dominem cada vez mais as competências que podem fazer a diferença para a sobrevivência e evolução de uma 
empresa em um mercado extremamente competitivo, sendo elas: as Soft Skills, Hard Skills, e as Digital Skills.

Com a pandemia da doença COVID-19, causada pelo vírus Sars-Cov-2, popularmente chamado de "Coronavírus", as empresas precisaram adotar medidas de afastamento e isolamento social, a fim de retardar os avançados da doença e impedir colapsos no sistema de saúde. Contudo, é necessário manter o fluxo da economia e o trabalho nas organizações. A prática do home office passou, então, a ser adotada por muitas companhias. Para que a realização das atividades rotineiras da organização nesta modalidade de trabalho se dê de forma eficiente, é necessário conhecer ferramentas digitais e ter habilidades pessoais para conseguir entregar os resultados necessários. Assim, contribui-se para o isolamento social no momento da crise, sem prejudicar o fluxo de informações e a tomada de decisão nas instituições, cooperando assertivamente com a economia do país.

O objetivo deste trabalho é demonstrar algumas Digital Skills, que podem ser de grande valia para as áreas de educação, coorporativa, comunicação e saúde, em um momento tão delicado como o vivido por ocasião da pandemia do COVID-19.

\section{PROBLEMA OBSERVADO}

No final do ano de 2019 um vírus colocou o mundo em alerta e fez as rotinas das pessoas serem alteradas, tendo sido declarado no início de 2020 pela Organização Mundial de Saúde (OMS) como sendo uma pandemia. A COVID-19 surgiu e está fazendo o mundo viver em um isolamento parcial. A falta de uma vacina e a alta velocidade de contágio influenciou de forma compulsória para que a mudança da rotina na sociedade fosse um ponto chave para combater a rápida proliferação da doença. A doença vem se mostrando mais grave em pacientes acima de 60 anos ou que apresentem outros problemas de saúde, como diabetes, problemas respiratórios, problemas cardíacos ou câncer. Esta parte da população, que naturalmente já requer mais cuidados médicos, se enquadra dentro de um grau de risco mais elevado. Assim, outro fator agravante na dificuldade do combate à pandemia é a incapacidade de atendimento nos hospitais pelas demandas elevadas.

Alguns países da Europa, a China e os Estados Unidos da América vêm sofrendo com altos números de pessoas infectadas e mortas. Em 27 de maio de 2020, o status global de pessoas 
infectadas, segundo o site COVID-19 Tracker ([2020]), plataforma para acompanhamento do vírus que foi desenvolvida pelo Google e pela equipe da Bing, era superior a 5.600.000 de casos, e o número de casos fatais já superava 354.000 .

As reuniões presenciais não são recomendadas nesse momento, de modo que liderar as equipes e entregar os resultados esperados precisam ser feitos remotamente, pois boa parte das empresas adotaram a prática do home office. Na verdade, esta modalidade de teletrabalho já é bastante difundida em alguns países. Na Suécia, por exemplo, segundo o Eurofound and the International Labour Office, em 2017, mais de 30\% dos empregados já contavam com a opção de trabalhar a partir de suas próprias residências. (EUROFOUND AND THE INTERNATIONAL LABOUR OFFICE, 2017).

A atual crise de saúde e sanitária reforçou ao homem que é possível ser criativo, analisar dados, tomar decisões, liderar equipes e entregar resultados de uma forma totalmente remota, com a utilização de aplicativos e ferramentas, que na sua grande maioria são gratuitas.

\section{FUNDAMENTAÇÃO TEÓRICA}

Conforme exposto, é necessário que as empresas busquem meios de continuarem operando nos momentos de crise. Com a pandemia gerada a partir da multiplicação desenfreada da COVID-19, as empresas adotaram algumas práticas que não faziam parte de suas rotinas, sendo algumas delas: Reuniões por vídeo conferência; Compartilhamento de documentos em drives na nuvem; Acesso remoto em outros computadores; Gerenciamento de projetos em programas compartilhados; Gerenciamento de equipes e Gerenciamento de rotina.

Alguns autores abordam temas sobre comunicação, novas tecnologias, sistemas de informação e meio de comunicação que trazem embasamento teórico sobre inovação dentro das organizações.

De acordo com Haubrich (2020) "o home office surgiu nos anos de 1970 com a crise do petróleo. Essa estratégia visava a amenizar problemas do trânsito, o que foi possível com o avanço das tecnologias e a competição empresarial em escala mundial."

Segundo Oliveira (2003, p. 145), "as corporações atuais necessitam encarar as inovações tecnológicas com muita ousadia, pois o próprio homem direcionou-as a um ponto onde não é mais possível parar de avançar tecnologicamente." 
Segundo Gonçalves (1993), a tecnologia é o fator particular de transformação de maior importância na modificação das empresas.

Conforme explicam Barizon, Pacheco e das Neves (2017), nos dias atuais, as organizações buscam novas estratégias que possam direcionar seu caminho e seu sucesso empresarial, atreladas a novos conceitos desenvolvidos neste novo mundo globalizado: Qualidade, Produtividade e Competitividade. Os resultados mais eficientes se darão para aquelas empresas que responderem de modo mais rápido às mudanças, demandas e necessidades do mercado consumidor e, principalmente, no atendimento aos anseios da sociedade quanto à inovação e com criação de valor (REZENDE, 2002).

De acordo com Prahalad e Hamel (1990), as empresas podem aplicar a gestão do conhecimento como estratégia de negócios, aplicando a teoria das competências essenciais e permitindo que a organização possa reagir de forma rápida às mudanças, a partir das habilidades específicas desenvolvidas e que devem ser preservadas.

Segundo O'Brien (2004), sistema de informação é um conjunto organizado de pessoas, hardware, redes de comunicações e recursos de dados que coleta, transforma e dissemina informações em uma organização, cuja função é o suporte aos processos e operações, na tomada de decisões e na estratégia em busca de vantagens competitivas.

Ainda, segundo Alvarenga Neto (2002) a gestão adequada de informações apoia o desenvolvimento da estratégia da organização.

A Tecnologia da Informação desempenha um papel crucial para o alcance dos objetivos das instituições (ALAVI; JOACHIMSTHALER, 1992).

Cabe ressaltar as pequenas diferenças entre os conceitos de trabalho remoto. Segundo a legislação trabalhista entende-se como Teletrabalho "a prestação de serviços preponderantemente fora das dependências do empregador, com a utilização de tecnologias de informação e de comunicação que, por sua natureza, não se constituam como trabalho externo". Ou seja, o teletrabalho engloba os trabalhos exercidos fora do local de trabalho, porém que poderiam ser exercidos da mesma forma se o empregado estivesse na sede de sua empresa. Já Trabalho Externo, é aquele que, por sua essência, necessita que o empregado se desloque e não poderia ser executado na própria empresa, como por exemplo: serviço de instalação de TV a cabo, serviço de inspeção de gás domiciliar, serviço de delivery etc. A leis trabalhistas preveem que o teletrabalho deverá constar expressamente no contrato do empregado. 
O Home Office, por sua vez, é uma modalidade excepcional de teletrabalho, podendo ser utilizado eventualmente pelos funcionários, sem a necessidade de previsão no contrato. Ele aparece como benefício eventual, utilizado uma vez por semana, ou medida emergencial, como no caso de catástrofes naturais, greve no transporte público ou, como está ocorrendo na atualidade, em prevenção contra doenças contagiosas.

\title{
4 METODOLOGIA
}

Para desenvolvimento do trabalho foi necessário realizar uma pesquisa em artigos científicos, e na internet para buscar algumas ferramentas digitais que facilitam o trabalho das empresas durante momentos de crise ou para flexibilizar tarefas que não precisam ser realizadas em um ambiente coorporativo, ferramentas que facilitam o trabalho remoto, e para isso é necessário ter conhecimento sobre Digital Skills, Soft Skills e Hard Skills.

De acordo com Gerhardt e Silveira (2009), a pesquisa é a atividade nuclear da Ciência. Ela possibilita uma aproximação e um entendimento da realidade a investigar. Basicamente pode ser dividida em qualitativa e quantitativa.

Conforme Fonseca (2002, p. 20):

\begin{abstract}
A pesquisa quantitativa se centra na objetividade. Influenciada pelo positivismo, considera que a realidade só pode ser compreendida com base na análise de dados brutos, recolhidos com o auxílio de instrumentos padronizados e neutros. A pesquisa quantitativa recorre à linguagem matemática para descrever as causas de um fenômeno, as relações entre variáveis, etc. A utilização conjunta da pesquisa qualitativa e quantitativa permite recolher mais informações do que se poderia conseguir isoladamente. (FONSECA, 2002, p. 20)
\end{abstract}

O trabalho em questão foi modelado nos padrões de uma pesquisa qualitativa. Segundo Gerhardt e Silveira (2009), a pesquisa qualitativa não se preocupa com representatividade numérica, mas, sim, com o aprofundamento da compreensão de um grupo social, de uma organização ou outras instituições em geral. O mesmo autor também demonstra as vantagens que o trabalho remoto pode proporcionar aos funcionários de uma organização, visto que podem impactar diretamente na qualidade de vida, na segurança, no descolamento e na produtividade nas atividades, conforme indica a Figura 1. 
Figura 1 - Vantagens do trabalho remoto

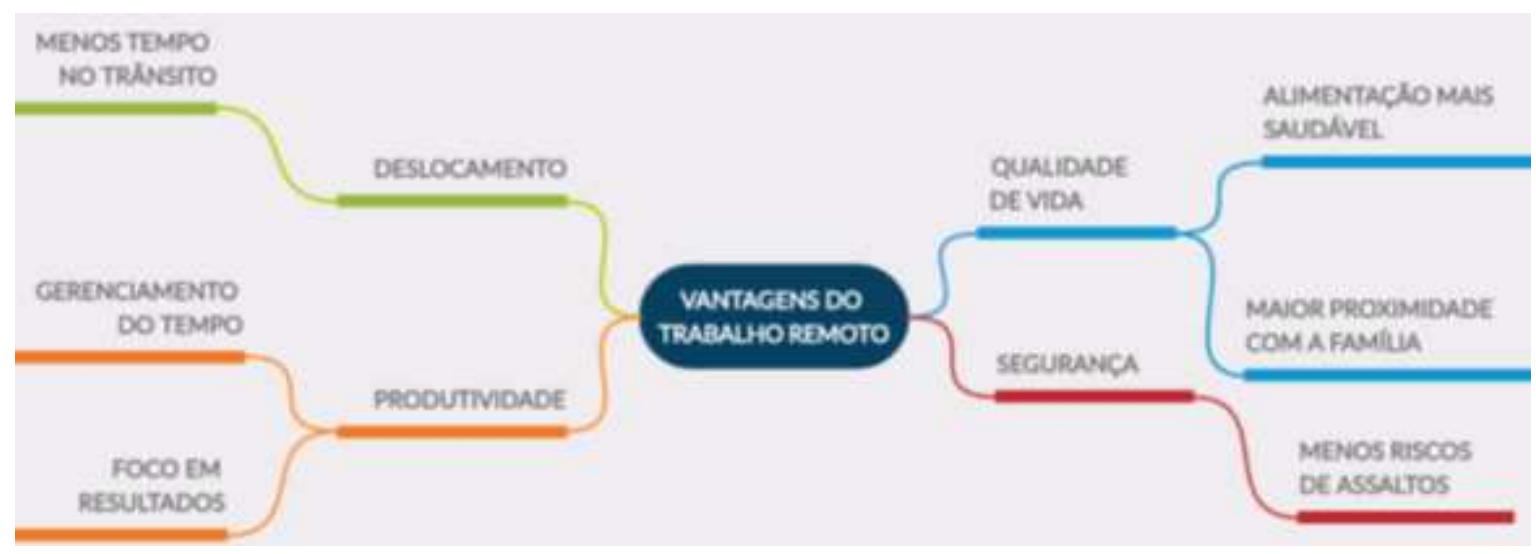

Fonte: Autores (2020)

Ainda conforme Gerhardt e Silveira (2009, p. 32):

As características da pesquisa qualitativa são: objetivação do fenômeno; hierarquização das ações de descrever, compreender, explicar, precisão das relações entre o global e o local em determinado fenômeno; observância das diferenças entre o mundo social e o mundo natural; respeito ao caráter interativo entre os objetivos buscados pelos investigadores, suas orientações teóricas e seus dados empíricos; busca de resultados os mais fidedignos possíveis; oposição ao pressuposto que defende um modelo único de pesquisa para todas as ciências. (GERHARDT; SILVEIRA, 2009, p. 32):

\section{FERRAMENTAS DIGITAIS}

Conforme exposto no decorrer do presente trabalho, as ferramentas digitais são fundamentais para que as empresas consigam superar a crise e vencer as barreiras impostas pelas ameaças externas. As Digital Skills, por sua vez, podem contribuir com o andamento de atividades chaves de uma organização e ajudar na manutenção de empregos, visto que se uma empresa observar que seu colaborador não necessita estar no escritório para realizar determinadas atividades, poderá adotar a prática do Home Office e manter o emprego do funcionário. 


\subsection{Acompanhamento e gerenciamento de projetos}

5.1.1. Trello

Figura 2 - Logo do aplicativo Trello

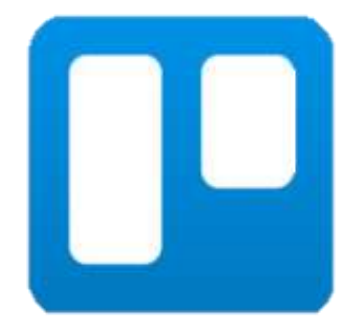

Fonte: Atlassian (c2020).

O Trello, ilustrado na Figura 2, é uma ferramenta simples, visual e muito intuitiva. A ferramenta funciona baseada em listas de tarefas e tem correlação direta com o Kanban, podendo ser utilizada em computadores e por aplicativos para smartphones.

Para utilizar basta criar um cadastro e começar a montar as listas de tarefas, nas quais é possível adicionar os dados dos projetos, os responsáveis pela execução e o prazo para a atividade ser realizada. O Trello possibilita visualizar de forma prática o que está em andamento e o que já foi concluído. Além disso, a ferramenta também permite integração com outros aplicativos, deixando os processos mais rápidos e automatizados. Na Figura 3, pode-se observar resumidamente o funcionamento do Trello.

Figura 3 - Funcionamento do Trello

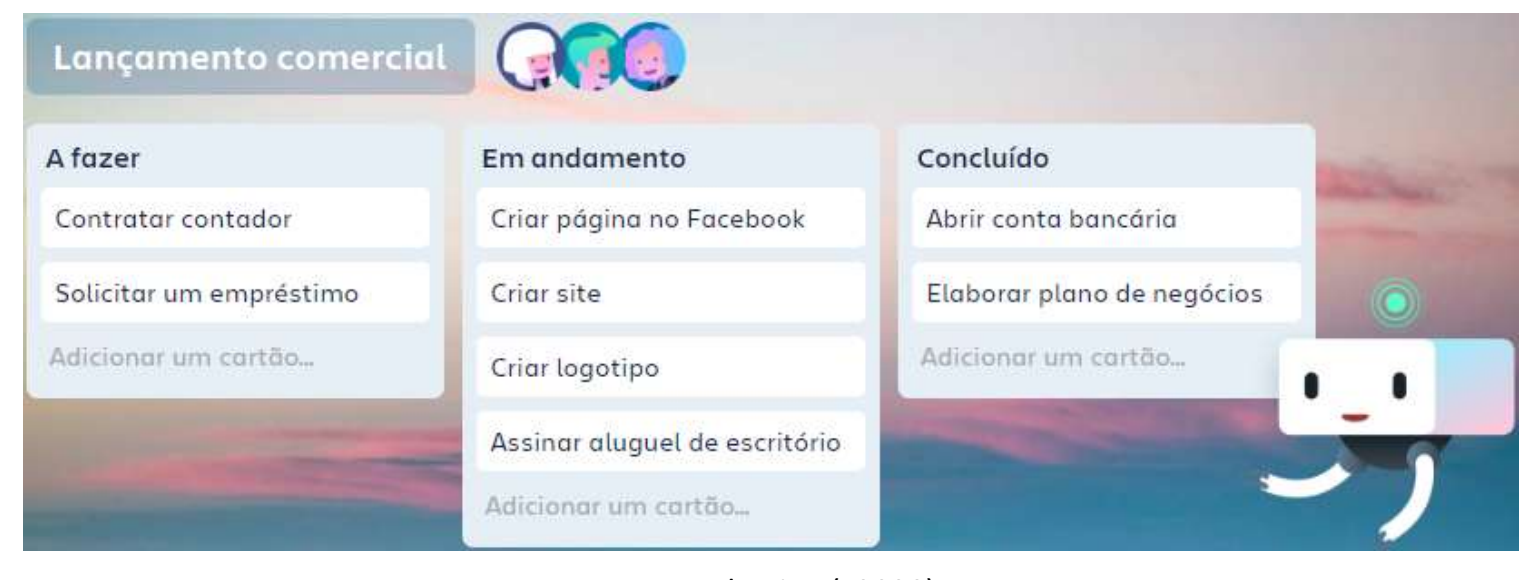

Fonte: Atlassian (c2020). 


\subsubsection{Asana}

O Asana, ilustrado na Figura 4, é uma ferramenta similar ao Trello, possibilitando, também, acompanhar e gerenciar os projetos da empresa de forma simples e visual. O Asana pode ser utilizado para soluções em diversas áreas, como Marketing, Operações, Vendas, Produto, Gestão de projetos, Gestão de fluxos de trabalho, Calendários, Quadros Kanban, Produtividade, Agile e Scrum.

Figura 4 - Logo do aplicativo Asana

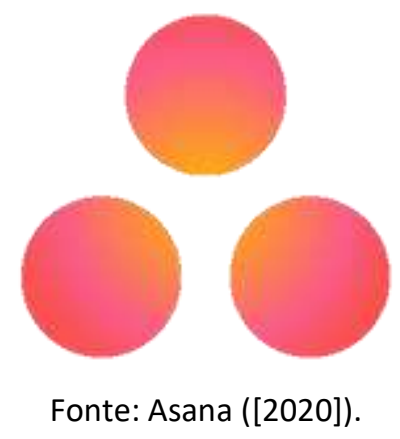

\subsection{Diálogos Constantes}

\subsubsection{WhatsApp}

O WhatsApp, ilustrado na Figura 5, é uma das ferramentas de comunicação mais conhecidas da atualidade, permitindo manter diálogos rápidos e de uma forma muito simples. O aplicativo também possibilita o compartilhamento de arquivos, contatos e localização, sendo possível ser utilizado por smartphones e computador, neste caso utilizando o $Q R$ Code.

Figura 5 - Logo do aplicativo WhatsApp

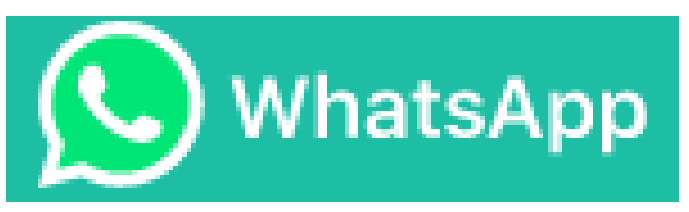

Fonte: WhatsApp Inc. (c2020). 


\subsubsection{Telegram}

O Telegram, ilustrado na Figura 6, é um aplicativo que oferece um serviço de mensagens instantâneas baseados na nuvem. Este programa permite o envio de fotos, vídeos, stickers e quaisquer tipos de arquivos. Pode ser utilizado em smartphones ou tablets, computadores e também como Aplicação web.

Figura 6 - Logo do aplicativo Telegram

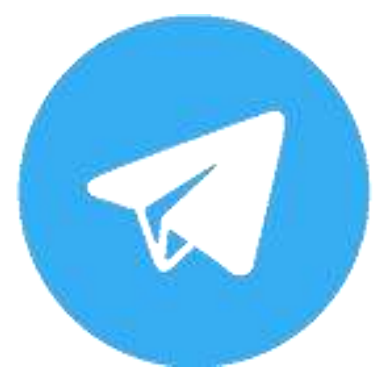

Fonte: Telegram ([2020]).

\subsection{Videoconferência}

\subsubsection{Zoom}

O Zoom, ilustrado na Figura 7, é uma ferramenta de comunicação visual. O programa é encontrado através de aplicativo para smartphones, também podendo ser utilizado em tablets, computadores ou afins. É gratuito, o que facilita a utilização por diversos tipos de grupos de pessoas. Ele pode ser utilizado para conversas informais, reuniões, videoconferência e até mesmo bate-papo escrito. 
Figura 7 - Logo do aplicativo Zoom

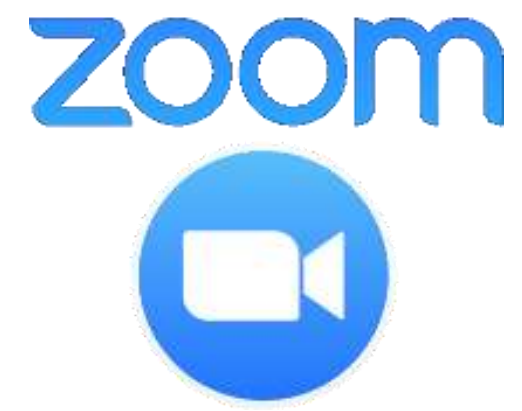

Fonte: Zoom Video Communications Inc. (c2020).

\subsubsection{Whereby}

O Whereby, ilustrado na Figura 8, é uma ferramenta que possibilita realizar videoconferências em poucos cliques. Esta plataforma de comunicação é compatível com os navegadores como Chrome, Safari e Firefox, e permite ingresso fácil em reuniões, bastando clicar em um link. O Whereby possui interface intuitiva e não necessita de download, facilitando seu acesso.

Figura 8 - Logo do aplicativo Whereby

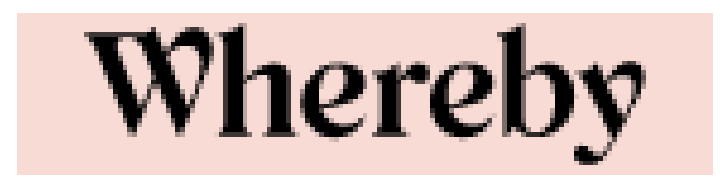

Fonte: Whereby (c2020).

\subsection{Plataforma de Design}

\subsubsection{Canva}

O Canva, ilustrado na Figura 9, é uma plataforma de design gráfico que permite desenvolver gráficos de mídia social, apresentações, fluxogramas, pôsteres entre outros. O programa está disponível de forma online e pode ser utilizado em dispositivos móveis em geral e integra diversos tipos de imagens, fontes, modelos e ilustrações. 
Figura 9 - Logo do aplicativo Canva

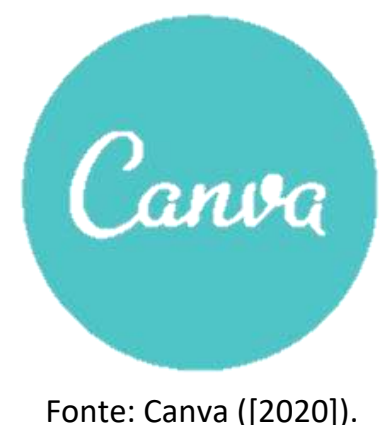

\subsection{Acesso Remoto}

\subsubsection{TeamViewer}

O TeamViewer, ilustrado na Figura 10, é um software próprio para o acesso remoto, compartilhamento de área de trabalho, conferência online e transferência de arquivos entre computadores. O programa opera dentro dos sistemas operacionais: Microsoft Windows, OS X, Linux, iOS, Android, Windows RT e Windows Phone.

Figura 10 - Logo do aplicativo TeamViewer

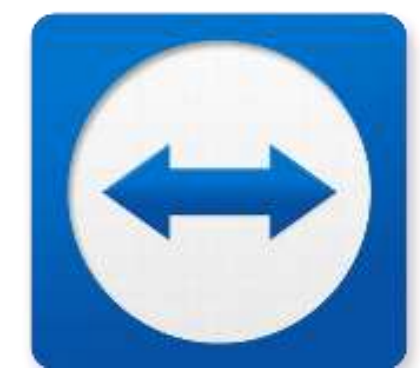

Fonte: TeamViewer ([2020]).

\subsubsection{AnyDesk}

O AnyDesk, ilustrado na Figura 11, é uma ferramenta proprietária de área de trabalho remota distribuída pela AnyDesk Software $\mathrm{GmbH}$. O programa de software fornece acesso remoto gratuito a computadores pessoais executando o aplicativo host, que pode ser instalado no Windows, macOS, Linux e FreeBSD. 
Figura 11 - Logo do aplicativo AnyDesk

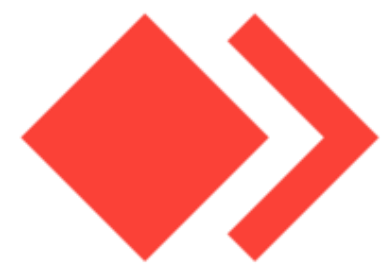

Fonte: AnyDesk (c2020).

\subsection{Organizador de Tarefas}

\subsubsection{FocusList}

O FocusList, ilustrado na Figura 12, é utilizado tanto para organizar as tarefas, quanto para realiza-las. Este programa faz uso da técnica Pomodoro, que sugere que se alterne 25 minutos de foco intenso com 5 minutos de descanso. O Programa permite inserir uma lista e a própria ferramenta a organiza entre mais curtas e mais longas de forma alternada para melhor produtividade.

Figura 12 - Logo do aplicativo Focuslist

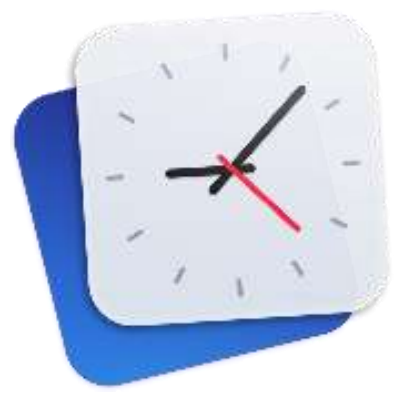

Fonte: FocusList (c2016).

\subsubsection{Any.Do}

O Any.Do, ilustrado na Figura 13, é um gerenciador de tarefas e listas gratuito para Android e iOS, excepcionalmente intuitivo e prático de se usar. A plataforma permite inserção de novas notas através de digitação, ou a voz, e permite eliminar de forma rápida quando a tarefa for concluída. Também existe uma versão paga na qual a ferramenta envia lembretes via WhatsApp, lembrando ao usuário que uma atividade precisa ser realizada assim que o mesmo 
chegar em determinado local, tendo em vista que é possível inserir a localização onde a tarefa precisa ser concluída.

Figura 13 - Logo do aplicativo Amy.Do

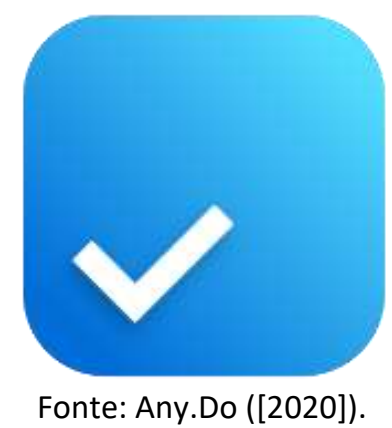

\subsection{Criação, Edição e Armazenamento de Documentos na Nuvem}

\subsubsection{Google Drive}

O Google Drive, ilustrado na Figura 14, é um serviço de armazenamento e sincronização de arquivos. Esta ferramenta permite que se faça upload de qualquer tipo de programa ou arquivo e os mantem sempre de forma organizada, facilitando o acesso. O Google Drive disponibiliza uma determinada memória e, quando a mesma se torna insuficiente, pode-se adquirir mais espaço de memória de acordo com a necessidade do usuário. A plataforma abriga agora o Google Docs, que possui um leque de aplicações de produtividade, que oferece a edição de documentos, folhas de cálculo, apresentações, entre outros.

Figura 14 - Logo do aplicativo Google Drive

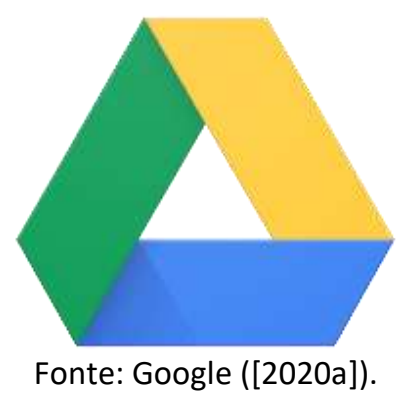




\subsubsection{OneDrive}

O OneDrive, ilustrado na Figura 15, é um serviço de armazenamento em nuvem da Microsoft. Com ele é possível armazenar e hospedar qualquer arquivo, usando uma Conta da Microsoft. Também é possível definir arquivos públicos, àqueles disponíveis somente a amigos, usuários definidos ou privados.

Figura 15 - Logo do aplicativo OneDrive

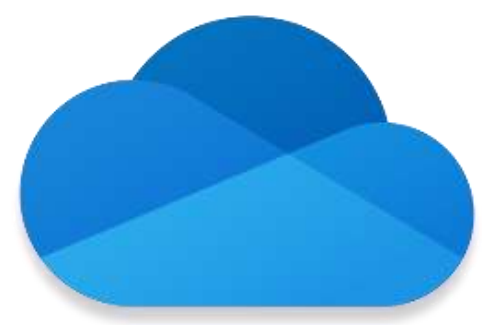

Fonte: Microsoft (c2020b).

\subsection{Elaboração de questionários, recolhimento de dados e gráfico das pesquisas em tempo real}

\subsubsection{SurveyMonkey}

O SurveyMonkey, ilustrado na Figura 16, é uma companhia baseada em nuvem de desenvolvimento de pesquisas online. Esta plataforma pode ser usada em diversas situações. Recentemente foi possível utilizar a ferramenta para realizar uma votação sobre quais áreas comuns seriam fechadas em um condomínio no Rio de Janeiro durante o período de quarentena: o sindico criou a pesquisa e todos os moradores puderam dar sua opinião de forma segura, democrática e em poucos segundos utilizando um aparelho smartphone.

Figura 12 - Logo do aplicativo SurevyMonkey

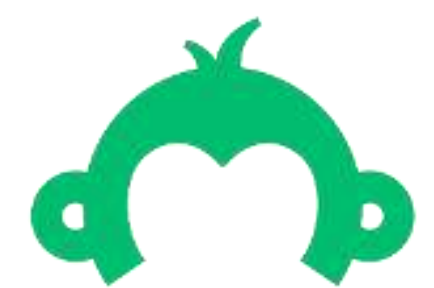

Fonte: SurveyMonkey (c1999-2020). 
Conforme demonstra a Figura 17, o criador da pesquisa consegue acompanhar o resultado da coleta de dados ou votação em tempo real e, com isso, tomar a melhor decisão para a solução do problema proposto.

Figura 17 - Utilização do SurveyMonkey na votação de um condomínio

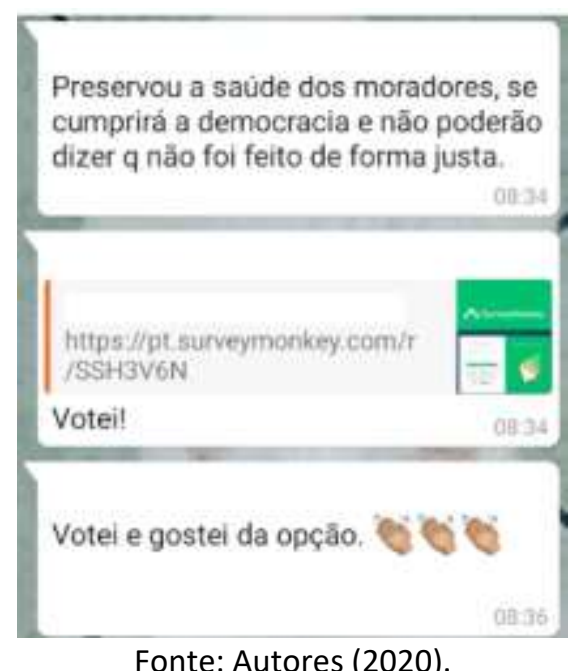

\subsubsection{Google Forms}

O Google Forms, ilustrado na Figura 17, é um aplicativo para fins administrativos no uso de pesquisas incluído no pacote do escritório do Google Drive, juntamente com o Google Docs, o Google Sheets e o Google Slides. O Forms normalmente é utilizado para coleta de dados e votação, podendo auxiliar no processo de tomada de decisão.

Figura 18 - Logo do aplicativo Google Forms

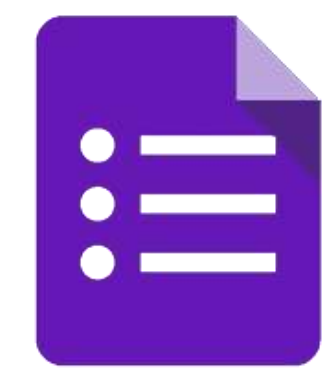

Fonte: Google ([2020b]). 
Como bônus ainda podem ser citados as ferramentas DocuSign e Microsoft Teams. $\mathrm{O}$ DocuSign, ilustrado na Figura 19, é uma solução para assinatura de contratos online: se houver a necessidade de assinar um contrato e ao mesmo tempo manter a segurança do isolamento social, de forma rápida, segura e com menos emissão de papeis, utilizar o DocuSign pode ser fundamental. Os documentos são criptografados e podem ser criados por um computador, tablet ou smartphone.

Figura 19 - Logo do aplicativo DocuSign

\section{DocuSign}

Fonte: DocuSign Inc. (c2003-2019).

O Microsoft Teams, ilustrado na Figura 20, é uma ferramenta multifuncional: a plataforma permite a realização de videoconferência, bate papo, ligações, armazenamento e compartilhamento de arquivos, gestão de equipes e projetos.

Figura 20 - Logo do aplicativo Microsoft Teams
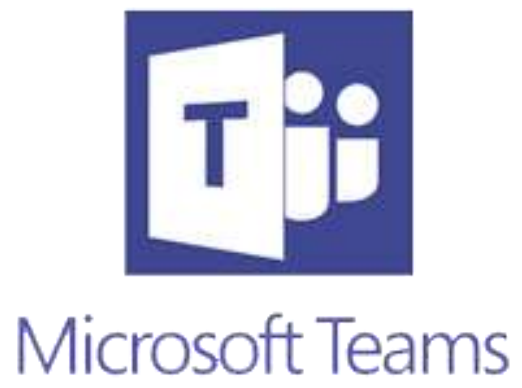

Fonte: Microsoft (c2020a).

A ferramenta permite fazer a integração com outros dispositivos, sendo, ao todo, mais de 400 aplicativos disponíveis, que podem ser pesquisados por categorias, sendo elas: Análises, Inteligência Artificial, Colaboração, Atendimento ao consumidor, Finanças, Recursos Humanos, Produtividade, Vendas, Marketing, Operações e TI. O objetivo é flexibilizar e automatizar os processos facilitando a entrega de resultados e a tomada de decisão. 


\section{CONSIDERAÇÕES FINAIS}

Após demonstrar as vantagens do trabalho remoto e apresentar algumas ferramentas que contribuam para o gerenciamento das atividades, com conferências virtuais, comunicação instantânea e edição e compartilhamento de documentos armazenados na nuvem, vale ressaltar que conhecer as ferramentas digitais é fundamental para as empresas conseguirem avançar positivamente no mercado competitivo e driblar os efeitos das ameaças externas, sendo elas; atentados, catástrofes naturais ou pandemias, como a da COVID-19 que influenciou a mudança da cultura organizacional de muitos negócios.

Ter domínio das Digital Skills, significa andar em paralelo com os avanços tecnológicos, utilizando as ferramentas de forma estratégica, as organizações podem continuar entregando produtos e serviços de qualidade em momentos de crise, estando assim um passo à frente na disputa mercadológica e na sobrevivência do negócio.

\section{REFERÊNCIAS}

ALAVI, M.; JOACHIMSTHALER, E. A. Revisiting DSS implementation research: A meta analysis of the Literature and suggestion for research. MIS Quarterly, p. 95- 116, Mar. 1992.

ALVARENGA NETO, R. C. Gestão da Informação e do Conhecimento nas Organizações: análise de casos relatados em organizações públicas e privadas. 2002. Dissertação (Mestrado em Ciência da Informação) - Programa de Pós-Graduação em Ciência da Informação, Escola de Ciência da Informação, Universidade Federal de Minas Gerais, Belo Horizonte, 2002.

ANY.DO. San Francisco: [S. n.], [2020]. Disponível em: https://www.any.do/. Acesso em: 30 mar. 2020.

ANYDESK. Alemanha: [S. n.], c2020. Disponível em: https://anydesk.com/pt. Acesso em: 30 mar. 2020.

ASANA. [S. I: s. n.], [2020]. Disponível em: https://asana.com/pt/product. Acesso em: 30 mar. 2020.

ATLASSIAN. Trello. [S. l]: Atlassian, c2020. Disponível em: https://trello.com/pt-BR. Acesso em: 30 mar. 2020.

BARIZON, B.-H. M.; PACHECO, M. C.; DAS NEVES, A. M. Agregando valor e gerando inovação com a implementação da gestão do conhecimento: um estudo aplicado às organizações de Tecnologia de Informação e Comunicação. In: SIMPÓSIO DE ENGENHARIA DE PRODUÇÃO, 5., 2017, Salvador. Anais [...]. Salvador: SIMEP, 2017. 
CANVA. [S. I: s. n.], [2020]. Disponível em: https://www.canva.com/. Acesso em: 30 mar. 2020.

COVID-19 tracker. [S. I: s. n.], [2020]. Disponível em: https://www.bing.com/covid. Acesso em: 03 abr. 2020.

DOCUSIGN INC. Docusign. San Francisco: c2003-2019. Disponível em: https://go.docusign.com. Acesso em: 02 abr. 2020.

EUROFOUND AND THE INTERNATIONAL LABOUR OFFICE. Working anytime, anywhere: the effects on the world of work. Luxembourg: Publications Office of the European Union; Geneva: International Labour Office, 2017.

FOCULIST. [S. I: s. n.], c2016. Disponível em: http://focuslist.co/. Acesso em: 30 mar. 2020.

FONSECA, J. J. Metodologia da pesquisa científica. Fortaleza: UEC. Apostila. 2002.

GERHARDT, T. E.; Silveira, D. T. Métodos de pesquisa. Porto Alegre: UFRGS. 2009.

GONÇALVES, J. E. L. Os impactos das novas tecnologias nas empresas prestadoras de serviço. Revista Administração de Empresas, v. 34, n. 1, p. 63-81, 1993.

GOOGLE. Google Drive. [S. I: s. n.], [2020a]. Disponível em: https://gsuite.google.com/intl/ptBR/products/drive/. Acesso em: 30 mar. 2020.

GOOGLE. Google Forms. [S. I: s. n.], [2020b]. Disponível em: https://gsuite.google.com/intl/ptBR/products/forms/. Acesso em: 30 mar. 2020.

HAUBRICH, Deise Bitencourt. Benefícios e Desafios do Home Office em Empresas de Tecnologia da Informação. Revista Gestão \& Conexões = Management and Connections Journal, Vitória, v. 9, n. 1, jan./abr. 2020.

MICROSOFT. Microsoft Teams. [S. I: s. n.], c2020a. Disponível em: https://products.office.com/pt-br/microsoft-teams/apps-and-workflows. Acesso em: 02 abr. 2020

MICROSOFT. Onedrive. [S. I: s. n.], c2020b. Disponível em: https://onedrive.live.com/about/ptbr/. Acesso em: 30 mar. 2020.

O'BRIEN, J. A. Sistemas de informação e as decisões gerenciais na era da internet. 2. ed. São Paulo: Saraiva. 2004.

OLIVEIRA, J. F. T.I.C: Tecnologia da informação e da comunicação. São Paulo: Érica, 2003.

PRAHALAD, C. K.; HAMEL, G. The core competence of the corporation. Harvard Business Review, v. 90, n. 3, p. 79-91, 1990. 
REZENDE, Y. Informação para negócios: os novos agentes do conhecimento e a gestão do capital intelectual. Ciência da Informação, Brasília, v. 31, n. 1, p. 75-83, 2002.

SURVEYMONKEY. [S. I]: Surveymonkey, c1999-2020. Disponível em: https://pt.surveymonkey.com/. Acesso em: 30 mar. 2020.

TEAMVIEWER. [S. I]: Teamviewer, [2020]. Disponível em: https://www.teamviewer.com/. Acesso em: 30 mar. 2020.

TELEGRAM. [S. l]: Telegram, [2020]. Disponível em: https://telegram.org/. Acesso em: 30 mar. 2020.

WHATSAPP INC. Whatsapp. [S. /]: Whatsapp Inc., c2020. Disponível em: https://www.whatsapp.com/. Acesso em: 30 mar. 2020.

WHEREBY. [S. /]: Whereby, c2020. Disponível em: https://whereby.com/. Acesso em: 30 mar. 2020.

ZOOM VIDEO COMMUNICATIONS INC. Reuniões Zoom. San Jose: Zoom Video, c2020. Disponível em: https://zoom.us/pt-pt/meetings.html. Acesso em: 30 mar. 2020.

Recebido em 18/02/2020

Aceito em 28/02/2020 